\title{
PODER CALORÍFICO DE Acacia dealbata Link CRECIDA EN CHILE ${ }^{1}$
}

\author{
Juan Carlos Pinilla S. ${ }^{2}$ y Gonzalo Hernández C.
}

\section{RESUMEN}

La creciente demanda energética y la inconveniencia de suplir esta demanda mediante combustibles fósiles, como el petróleo y sus derivados, el carbón mineral y el gas natural, dados su costo, su carácter de recurso no renovable y sus altos niveles de emisiones de gases de efecto invernadero, están poniendo en especial relieve a las energías renovables y menos contaminantes.

La dendroenergía, o energía procedente de combustibles leñosos, es un recurso renovable y es considerada carbono neutral, debido a que su combustión libera carbono antes captado por los vegetales mediante la fotosíntesis para la formación de la madera, sin intervenir por tanto en el balance global de este elemento, que es el principal gas de efecto invernadero bajo la forma de dióxido de carbono $\left(\mathrm{CO}_{2}\right)$.

Los combustibles leñosos pueden ser utilizados directamente para producir energía calórica mediante su combustión o indirectamente a través de cogeneración, donde su energía calórica en calderas calienta agua y genera vapor, el cual se usa para distribuir calor mediante ductos y además como energía mecánica que mueve turbinas generadoras de energía eléctrica. Otro uso es la gasificación de madera, sistema en el que una combustión incompleta, con limitada presencia de oxígeno, genera un gas combustible que es empleado para alimentar un motor de combustión interna modificado, generando así energía mecánica que mueve un generador de electricidad.

La dendroenergía proviene de los bosques, sean estos nativos o plantados, y se obtiene del manejo de estos, como residuos de podas, raleos y cosechas de bosques destinados a producir madera aserrada, celulosa, tableros y otros productos, o como producto sin un bosque se maneja expresamente para este fin. Además, la industria de transformación de la madera, primaria y secundaria, genera también importantes volúmenes de residuos.

Bosques nativos comerciales y bosques plantados, destinados a proveer productos forestales de mayor valor como los mencionados, dejarán importantes volúmenes de residuos en cada intervención silvícola a la que son sometidos para favorecer los productos finales. En el caso de los bosques nativos, bajo manejo forestal sostenible nunca se afectará la superficie boscosa sino que solo su volumen comercial al extraer los productos, luego continúa creciendo hasta permitir una nueva extracción. Las plantaciones en tanto, normalmente al cumplir su

1 Documento elaborado en el marco del proyecto INNOVA CHILE - CORFO 07CN13IFM-203, Programa Acacia para su uso 
período de rotación son cortadas a tala rasa, pero son inmediatamente repuestas para iniciar una nueva rotación.

Bosques nativos sobremaduros o degradados deben ser manejados para hacerlos productivos y las intervenciones silvícolas necesarias para su recuperación generan importantes volúmenes de leña y residuos. Algo semejante ocurre con bosques nativos jóvenes o renovales, que han surgido después de incendios o de sobreutilización de los bosques originales en el pasado y ahora son formaciones de excesiva densidad y a menudo con una alta participación de las especies de menor crecimiento o valor, las cuales es preciso intervenir para reducir la densidad y favorecer su desarrollo, en especial de las especies más valiosas. El manejo de estos renovales puede ser también una importante fuente de leña y residuos leñosos combustibles.

En uno y otro caso, bosques nativos y plantados, bajo ciertas circunstancias pueden ser manejados para la producción de dendroenergía. En el caso particular de las plantaciones, en diferentes países se emplean especies de los géneros Acacia, Eucalyptus, Populus, Salix y otros, en plantaciones de corta rotación y con altos rendimientos para energía.

El Instituto Forestal ha desarrollado diversas experiencias en la materia, parte de estas a través de un amplio programa de investigación con especies de género Acacia, orientado a determinar su crecimiento en diferentes zonas del país, su manejo y su utilización, y ha iniciado también ensayos de plantaciones con fines energéticos. En el presente trabajo se entregan antecedentes sobre las potencialidades de Acacia dealbata y, específicamente sobre la determinación de su poder calorífico, importante información para su uso con fines energéticos.

Palabras Clave: Acacia dealbata, biomasa, energía, poder calorífico

\section{SUMMARY}

The energy increasing demand and the inconvenience to supply it through fossil fuels, such as petroleum and its derivatives, coal and natural gas, considering their costs, their character of nonrenewable resources and their high level of green house gases emissions, are factors giving a special importance to renewable and lesser contaminant energies.

Wood energy is a renewable resource and, since its combustion releases a quantity of carbon equal to that captured before to constitute the wood through the photosynthesis process, is considered as a neutral one in terms of carbon emissions because does not participate in the global carbon balance, main green house gas under the form of carbon dioxide $\left(\mathrm{CO}_{2}\right)$.

Wood energy can be used to produce caloric energy directly through its combustion or to heat water in boilers and produce steam to distribute caloric energy by pipelines and also mechanic energy to drive a turbine for generating electric energy. Another application is wood gasification, system by which wood is burned under a poor oxygen condition generating a combustible gas to feed a modified internal combustion engine that moves a turbine to produce electric energy. 
Forest management in native or planted forests produces a quantity of residues from thinning, pruning and harvest silvicultural practices, suitable for energy production. Primary and secondary wood transformation industries generate also important waste volumes.

Commercial native and planted forests used to produce sawn wood, pulp, boards and veneers, and other forest products, give also an important waste volume as a result of the silvicultural interventions applied to favor the final products. In native forests under sustainable management extractive practices do not reduce the forest area only reduce the commercial volume and the forest will continue growing until allowing another intervention. Planted forests are normally completely felled at the end of the turn, but they are immediately replaced through a new plantation to begin another turn.

Overripe or degraded native forests have to be managed to turn they productive and the necessary silvicultural practices generate important waste volumes. Young or second growth forest originated in forest fires or over utilization of the original ones in the past, now dense forests often with a high participation of minor species, have also to be managed to reduce the number of trees and to favor the better trees and the most valuable species. The management of second growth forest also can be an important source of fuel wood and waste wood materials for energy uses.

Both, native and planted forests can be managed for energy production under certain circumstances and in the case of planted forests, in different countries species of the Acacia, Eucalyptus, Populus, Salix and others genera are used in short rotation and high yield plantations for energy.

The Chilean Forest Institute has carried out several experiences on the matter, part of them though a wide wattle species research programme focused on their growth under different site conditions, their management and their wood utilization, and has started also the establishment of experimental plantations for energy production. In the present paper information on the Acacia dealbata potential for energy plantations is analyzed and specifically results on the species heating power are presented.

Key Words: Acacia dealbata, biomass, energy, heating power.

\section{INTRODUCCIÓN}

Las fuentes energéticas son primarias o secundarias y entre las primeras las hay renovables y no renovables. Las fuentes primarias están dadas por recursos naturales disponibles para su uso energético en forma directa, sin necesidad de someterlas a un proceso de transformación, o en forma indirecta, como es el caso de aquellas que deben ser extraídas de yacimientos.

Las fuentes de energía primarias son además renovables, de uso sostenible en el tiempo, si la fuente no se consume o puede ser repuesta, y no renovables, de uso limitado en el tiempo, si el recurso natural se consume. 
Entre las energías primarias renovables se encuentran la hidráulica, la marina, la eólica, la geotérrmica, la solar y la procedente de biomasa, y entre las no renovables están los combustibles fósiles, como el petróleo, el gas natural y el carbón mineral, y la energía nuclear.

Las fuentes secundarias corresponden a productos procesados, obtenidos de la transformación de las fuentes primarias, como combustibles derivados del petróleo, del carbón mineral y del gas natural. También es considerada energía secundaria la electricidad, obtenida por la transformación de energía mecánica, como la hidráulica y la eólica, o energía térmica, como la solar, la geotérmica, el petróleo, el carbón y el gas, en energía eléctrica.

La demanda energética es creciente en Chile y en el mundo y la dependencia de los combustibles primarios no renovables es muy alta, lo que conduce a que principalmente los países no productores de combustibles fósiles presenten cifras muy negativas en sus balances energéticos, al registrar consumos muy superiores a su producción en materia de energía, situación que los obliga a importar estos combustibles con todos los costos que esto implica.

Se suman a lo anterior las grandes desventajas ambientales del uso de combustibles fósiles, dadas por las altas emisiones de gases de efecto invernadero (GEI) que implica su empleo.

Las actuales concentraciones de estos gases en la atmosfera están provocando el fenómeno conocido como calentamiento global y conduciendo a un cambio climático en el planeta que, de mantenerse las emisiones de estos gases al ritmo de hoy, tendría impredecibles consecuencias para la vida sobre este, ya que subirían las temperaturas, se alterarían los regímenes de precipitaciones, se elevaría el nivel de los océanos, aumentaría la frecuencia e intensidad de eventos climáticos extremos, como sequías o fuertes lluvias, y otras alteraciones del clima o asociadas a este.

La urgente necesidad de reducir las emisiones de GEI y estabilizar sus concentraciones en la atmosfera en límites aceptables, ha conducido a diversos acuerdos internacionales tendientes a disminuir el consumo de combustibles fósiles y frenar la deforestación, que son los dos agentes principales de estas.

Esta situación pone en una especial relevancia a los bosques, más allá de su generación de productos forestales, dado que además son capaces de absorber carbono a través de la fotosíntesis y fijarlo en sus tejidos y en el suelo, mantener este elemento retenido en sus productos (madera, celulosa, muebles, casas, etc.) y proveer grandes volúmenes de combustible leñosos o dendroenergía para reemplazar el uso de fósiles.

Los bosques nativos bajo manejo sostenible pueden a perpetuidad retener carbono y producir leña y residuos de la intervenciones silvícolas de manejo y de los procesos de transformación industrial de la madera. Las plantaciones forestales en tanto, también generan residuos de la silvicultura y de la industria de transformación, y además es posible efectuar plantaciones con fines energéticos que, en cortas rotaciones, pueden ofrecer importantes volúmenes de dendroenergía. 
En términos de emisiones, la dendroenergía es considerada carbono neutral debido a que su combustión libera igual cantidad de carbono que la que antes el árbol absorbió para su formación. Además, si proviene de bosques nativos bajo manejo sostenible, estos continuarán creciendo y reteniendo y fijando carbono, y si proviene de plantaciones, que son cortadas a tala rasa, estas, dependiendo de la especie que se emplee, crecerán nuevamente en régimen de monte bajo o serán respuestas mediante plantación en régimen de monte alto, cosa por demás obligatoria por ley en el caso de Chile.

El uso de dendroenergía tiene ciertos inconvenientes en materia de emisiones, en especial en centros urbanos y principalmente debido al material particulado que contribuye al smog, y en materia de degradación de los bosques, por el caso específico de la leña, cuyo mercado es informal y con escasa o nula regulación. Sin embargo, su empleo es ampliamente ventajoso ambientalmente en comparación con petróleo, carbón u otros fósiles.

Respecto de las emisiones, existe ya en el mercado una variedad de calefactores y cocinas de gran eficiencia energética respecto de las tradicionales y con reducidos niveles de emisiones, y a esto se suma la creciente tendencia a emplear leña con menores contenidos de humedad y otras formas de dendroenergía, como astillas y pellets, lo que contribuye con similares resultados en lo referente a emisiones y a eficiencia.

En cuanto a la presión sobre los bosques que implica el uso de dendroenergía, se debe considerar una amplia utilización de todos los desechos de la silvicultura y de la industria forestal, tema sobre el cual existen ya importantes avances; las grandes empresas forestales, mediante procesos de cogeneración, están produciendo vapor y energía eléctrica a partir de sus residuos para su propio consumo y generando excedentes de electricidad que están entregando al $\mathrm{SIC}^{3}$. Actualmente la capacidad instalada de este tipo de generación ya supera los 600 MW.

Por otra parte, el gran desafío del manejo sostenible de los bosques está apoyado por la legislación forestal chilena, que fomenta las plantaciones forestales y el manejo de los bosques nativos, lo que debe conducir a que el mercado de la leña se regule, al menos en lo referente al origen de esta, ofreciendo una garantía de que proviene de bosques bajo manejo, y también a que se establezcan plantaciones forestales con fines energéticos.

Respecto de las plantaciones forestales para energía, INFOR está desde hace años trabajando con diversas especies cuyas alternativas de uso incluyen la energía y reúnen también características de rápido crecimiento, fácil propagación y establecimiento, bajas exigencias en suelos y buen poder calorífico de su madera, todas las cuales las hacen muy apropiadas para este tipo de plantaciones.

Entre las especies en estudio que serían adecuadas para plantaciones energéticas se encuentran varias de los géneros Eucalyptus y Acacia, con las cuales se han desarrollado diversas líneas de investigación en torno a su propagación, al establecimiento de plantaciones, a su silvicultura, a la utilización de sus maderas y, además, se realizan estudios sobre su mejoramiento genético para una mejor adaptación y rendimiento bajo diferentes sitios

3 Sistema Interconectado Central. Sistema de distribución de energía electrica de la zona central y sur del país en Chile. 
forestales.

Como parte de estas investigaciones se han iniciado estudios sobre el poder calorífico de sus maderas y en el presente trabajo se entregan los resultados obtenidos al respecto para Acacia dealbata.

\section{ANTECEDENTES GENERALES}

\section{Matriz Energética}

La matriz energética chilena es ampliamente dependiente de los combustibles fósiles pese a que el país cuenta con un gran potencial para la hidrogeneración.

El alto costo del petróleo, los problemas ambientales que involucra su uso y el del gas y el carbón mineral, y la dependencia que significa el importar estos combustibles, son factores que otorgan actualmente un especial interés al desarrollo de las llamadas Energías Renovables No Convencionales (ERNC), entre las que se cuentan la eólica, la hidráulica de paso, la geotérmica, la solar, la marina y la biomasa.

El consumo total de energía en el país en 2008, de acuerdo a la Comisión Nacional de Energía $(\mathrm{CNE}, 2009)^{4}$, muestra un total de $251 \mathrm{mil} \mathrm{T} \mathrm{Cal}^{5}$. Un $71 \%$ de esta energía se obtiene de combustibles fósiles y un $62 \%$ se obtiene de importaciones de estos, debido a que sólo una parte de estos se produce en el país (Figura $\mathrm{N}^{\circ} 1$ ).

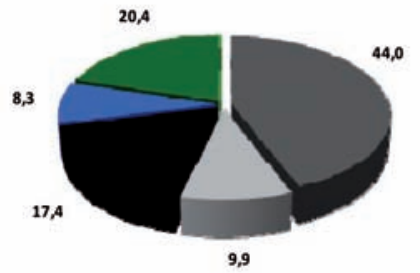

9,9

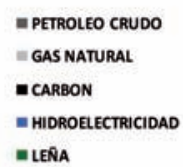

ELENA

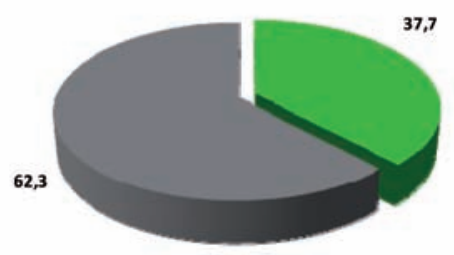

- Producción Bruta = Importación

(Fuente: CNE, 2009)

Figura $N^{\circ} 1$

CONSUMO TOTAL ENERGÍA 2008

La capacidad instalada nacional de generación eléctrica en el año 2008 es de 13 mil $\mathrm{MW}^{6}$, conformada por 8 mil MW procedentes de plantas térmicas alimentadas por petróleo y carbón mineral, 4,8 mil MW provistos por centrales hidroeléctricas de embalses, y unos $350 \mathrm{MW}$ generados por plantas hidroeléctricas pequeñas de paso, plantas cogeneradoras basadas en biomasa y parques eólicos.

$4 \mathrm{http}: / /$ www.cne.cl/cnewww/opencms/

5 Tera Calorías

6 Mega Watts 


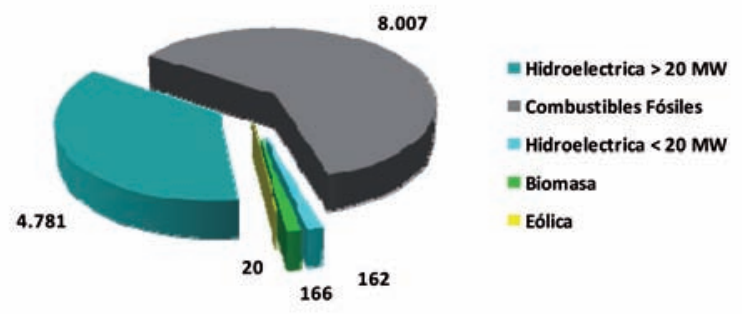

Figura $\mathrm{N}^{\circ} 2$

CAPACIDAD INSTALADA GENERACIÓN ELÉCTRICA 2008

La capacidad instalada total de generación al año 2008 está basada en un $61 \%$ en combustibles fósiles y sólo un 2,6\% corresponde a ERNC, con un cierto aporte de parques eólicos en las regiones de Coquimbo y Aysén y un desarrollo ya visible de la generación basada en biomasa, que en la actualidad llega a más de 600 MW, principalmente en la región del Bio Bio y operado por las principales empresas forestales.
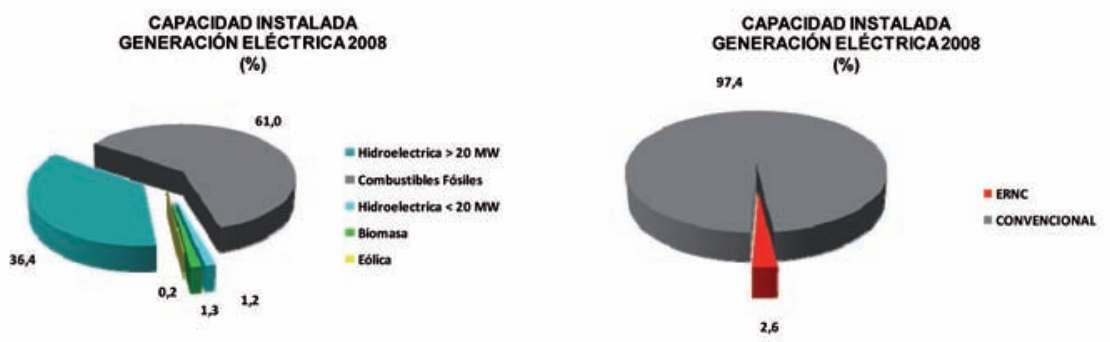

Figura $\mathrm{N}^{\circ} 3$

CAPACIDAD INSTALADA GENERACIÓN ELÉCTRICA SEGÚN FUENTE 2008

La capacidad instalada de generación eléctrica se ha cuadruplicado entre 1990 y $2007^{7}$, sin embargo el consumo es alto y crece fuertemente, desde 1990 hasta 2008 este prácticamente se ha duplicado, y el consumo en 2007 es 2,5 veces mayor que la producción ${ }^{8}$ (Figura $\mathrm{N}^{\circ} 4$ ). 

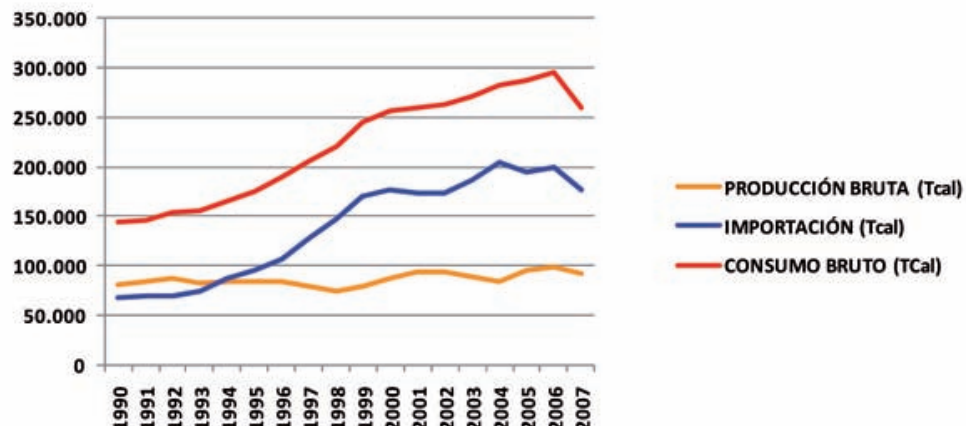

Figura $\mathrm{N}^{\circ} 4$

EVOLUCIÓN DEL BALANCE NACIONAL DE ENERGÍA 1990-2007

Si se considera la dependencia energética y el alto costo que involucran los combustibles fósiles que es preciso importar, muy especialmente el petróleo, y la imperiosa necesidad de reducir las emisiones de GEI que estos generan en abundancia, es sin duda un objetivo estratégico país el desarrollo de las ERNC para ampliar y diversificar su matriz energética. Entre estas, destaca la biomasa, fuente primaria y renovable, que los bosques chilenos y la industria derivada de estos pueden proporcionar a perpetuidad, dentro de un principio de sustentabilidad.

\section{Biomasa}

Se entiende por biomasa al conjunto de materia orgánica renovable, de origen vegetal, animal o que se origina de la transformación natural o artificial de estas, y la energía de biomasa es toda aquella energía que puede obtenerse de esta, sea a través de su quema directa o de su procesamiento para obtener otro tipo de combustible (biogás, biocombustibles líquidos) ${ }^{9}$.

La energía de biomasa tiene su origen primario en la radiación solar que los vegetales emplean en la fotosíntesis, proceso en el que en presencia de esta radiación los vegetales absorben dióxido de carbono $\left(\mathrm{CO}_{2}\right)$, liberan oxígeno $\left(\mathrm{O}_{2}\right)$ y producen los compuestos orgánicos para su crecimiento, según la ecuación general:

$$
6 \mathrm{CO}_{2}+6 \mathrm{H}_{2} \mathrm{O} \rightarrow \mathrm{C}_{6} \mathrm{H}_{12} \mathrm{O}_{6}+6 \mathrm{O}_{2}
$$

De esta forma, los vegetales almacenan parte de la energía solar y el ser humano y los animales la transforman, y en ambos procesos se generan diversos residuos que son susceptibles de aprovechamiento energético (Figura $N^{\circ} 5$ ). 


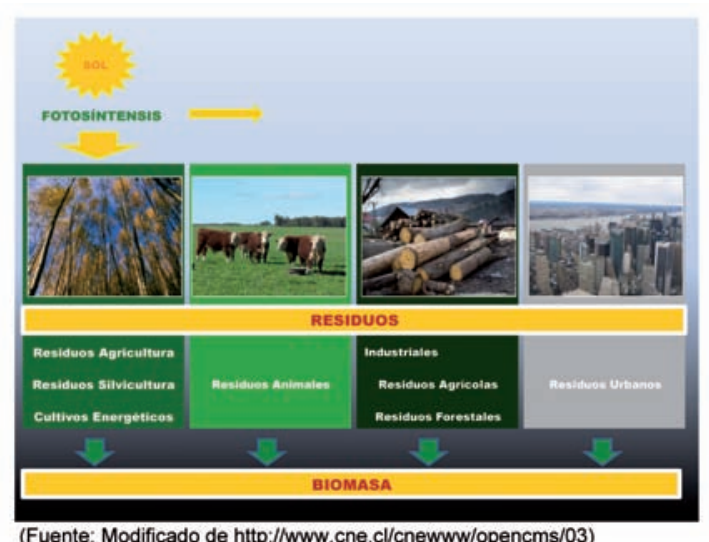

(Fuente: Modificado de http://www.cne.cl/cnewww/opencms/03)

(Fuente: Modificado de http://www.cne.cl/cnewww/opencms/03)

\section{Figura $\mathrm{N}^{\circ} 5$ \\ FUENTES DE BIOMASA UTILIZABLE COMO ENERGÍA}

Ante los acuerdos internacionales de reducciones de emisiones de GEI la biomasa tiene un factor de emisión 0 , es considerada carbono neutral al ser usada con fines energéticos debido a que su combustión produce $\mathrm{CO}_{2}$ en la misma cantidad que antes fue captada de la atmosfera para el crecimiento del vegetal, y esta cantidad es también la misma que liberaría si se la deja descomponerse en forma natural. No obstante, si se la usa en reemplazo de combustibles fósiles, contribuye significativa a la reducción de emisiones.

La Comisión Nacional de Energía (CNE, 2009) ${ }^{10}$ señala que hay diferentes fuentes de biomasa utilizable para energía y que la clasificación más aceptada es la siguiente:

Biomasa natural: Presente en la naturaleza sin intervención humana. Ejemplo: Residuos naturales en los bosques.

- Biomasa residual seca: Desechos sólidos no utilizados de la agricultura, ganadería y silvicultura, y de los procesos industriales agrícolas, ganaderos y forestales. Ejemplos: Estiércol, paja, orujo, desechos de podas y raleos, aserrín, corteza y otros.

- Biomasa residual húmeda: Vertidos biodegradables. Ejemplo: Aguas residuales urbanas e industriales, y residuos ganaderos, que por fermentación pueden generar un gas (biogás) combustible.

- Cultivos energéticos: Cultivos realizados con la finalidad de producir biomasa para energía o para producir biocombustibles. Ejemplo: Maíz, raps, maravilla y plantaciones forestales dendroenergéticas.

10 http://www.cne.cl/cnewww/opencms/03_Energias/Otros_Niveles/renovables_noconvencionales/Tipos_Energia/ biomasa.html 
Los usos de la biomasa en aplicaciones energéticas son principalmente la producción de gas, energía calórica y energía eléctrica. En Chile se la está utilizando actualmente para producir electricidad, mediante plantas de cogeneración que aprovechan los residuos energéticos de la silvicultura, la agricultura, las industrias forestales, y biogás a partir de vertederos de desechos urbanos.

Los bosques generan importantes volúmenes de biomasa, sea como producto o como residuos de la extracción de estos.

Bosques nativos degradados o sobre maduros y algunos renovales pueden generar grandes volúmenes de leña, como producto principal al ser puestos bajo manejo para una futura obtención de productos de valor como madera aserrada, tableros, chapas y otros. Plantaciones forestales en tanto, pueden ser establecidas para uso energético con especies de rápido crecimiento, en alta densidad de plantación y para cortas rotaciones.

Los bosques nativos productivos son sometidos a diferentes intervenciones silvícolas para su manejo y extracción de productos y en estas quedan importantes volúmenes de residuos, como trozas cortas, ramas y otros.

Las plantaciones comerciales, según el producto final a obtener, son sometidas a diferentes intensidades y oportunidades de raleos y podas y todas estas, incluida la cosecha final, dejan importantes cantidades de residuos en el bosque, dadas por trozas cortas o muy delgadas, ramas y otros.

El procesamiento industrial primario de las trozas obtenidas de los bosques, sean nativos o plantados, también tiene cantidades importantes de residuos. Las trozas de bosque nativo se emplean principalmente para aserrío y el rendimiento de este proceso es inferior al $50 \%$, generando así grandes volúmenes de madera exterior (tapas y cantoneras), madera con defectos, aserrín y otros residuos.

El procesamiento de las trozas obtenidas de plantaciones es en las grandes empresas del sector es mucho más eficiente. La industria de pulpa y papel solo deja como residuos la corteza y desechos químicos originados en la separación de la celulosa y la lignina (licores negros), pero dados los grandes volúmenes que procesa estos residuos son importantes y son utilizados con fines energéticos en las mismas plantas. En el caso del aserrío, si bien tiene un rendimiento cercano al $50 \%$, todos los residuos de madera son astillados y destinados a las plantas de celulosa.

La industria secundaria en tanto, remanufactura, barracas, mueblería y otras, tanto para bosque nativo como para plantaciones, tiene igualmente cantidades de desechos, dados por aserrín, despuntes, cantos, virutas, polvo de madera y otros.

En el caso de la pequeña y mediana industria de aserrío y elaboración, tecnologías y máquinas son más precarias, los rendimientos son menores y en consecuencia mayor la proporción de residuos 


\section{Acacia dealbata como Opción Dendroenergética}

Acacia es un género de arbustos y árboles de la Familia Leguminosae, Subfamilia Mimosoideae, compuesto por más de 1300 especies, que se distribuyen en forma natural en todos los continentes con la excepción de Europa. Más de 900 de estas especies son nativas de Australia y las restantes de las regiones tropicales secas y templadas cálidas de África, sur de Asia y América (Barros, 2007).

Acacia dealbata Link. Correponde al Subgénero Phyllodineae, es originaria de Australia y su área de distribución natural abarca principalmente los Alpes australianos, desde el norte del estado e New South Wales el medio oeste del de Victoria y la Isla de Tasmania, entre los 29 y $43^{\circ}$ LS, principalmente entre los 250 y 900 msnm (Barros, 2007) (Figura № 6).
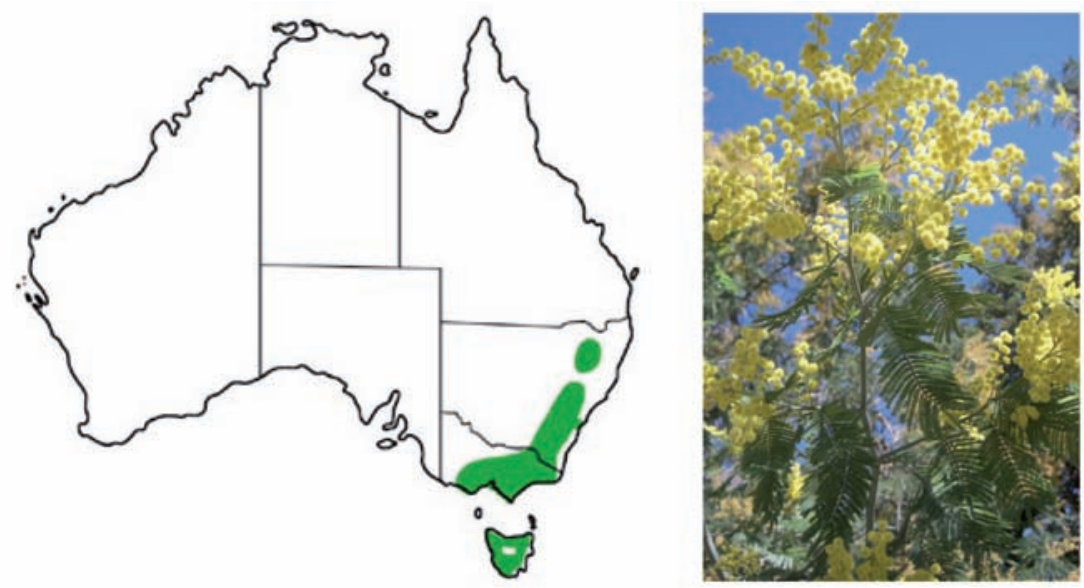

(Fuente: DEWR, 2007. Citado por Barros, 2007)

Figura $N^{\circ} 6$

\section{DISTIBUCIÓN NATURAL DE Acacia dealbata Y ASPECTO DEL ÁRBOL CON FLORES}

Es un arbusto o árbol de rápido crecimiento, fijador de nitrógeno, que puede alcanzar desde 6 a 30 m de altura. El follaje es bipinnado, azul-gris a plateado. Las flores son Amarillo oro, en cabezas globulares y florece abundantemente. Las vainas son más o menos rectas, planas, levantadas sobre las semillas y de color café-purpúreo suave. Presenta unas 53.000 semillas viables por kilo de semillas y deben ser pretratadas en agua hirviente por un minuto para mejorar la germinación en viveros (DEWR, 2007. Citado por Barros, 2007).

En Australia la especie es conocida como Silver Wattle en tanto que en Chile se la conoce como aromo o aromo del país. Fue introducida tempranamente a Chile, muy probablemente por el naturalista alemán Federico Albert ${ }^{11}$ a fines del siglo XIX, y hoy es común en la zona central

11 Federico Albert naturalista alemán contratado por Gobierno de Chile en 1889 para trabajar en el Museo Nacional de Historia Natural de Santiago, quien fue el primer visionario que impulsó el desarrollo forestal en Chile, considerando 
y sur del país (Coquimbo a La Araucanía) como ornamental y en bosquetes en los campos.

El Instituto Forestal (INFOR) está desarrollando desde el año 2003, apoyado por INNOVA Chile de CORFO, un intenso programa de investigación con especies del género Acacia, el cual ha abordado los aspectos de propagación, establecimiento de plantaciones, manejo silvícola y utilización de sus maderas, y ha incluido en estas investigaciones Acacia dealbata, $A$, melanoxylon y A. mearnsii.

Este programa ha obtenido muy auspiciosos resultados respecto de la adaptación de estas especies a diferentes condiciones de sitio, su rápido crecimiento y la utilidad de sus maderas. Esto las torna muy interesantes también como alternativa para la producción dendroenergética, ya que pueden ser empleadas en plantaciones para este fin en rotaciones de 3 a 5 años, una forma eficiente y segura de generar dendroenergía, con un alto rendimiento por unidad de superficie y obteniéndose materia prima uniforme, lo que otorga una gran ventaja a esta alternativa frente al uso de residuos forestales no homogéneos y dispersos.

Existen diversas experiencias en el mundo con plantaciones dendroenergéticas, con diferentes especies de los géneros Acacia, Eucalyptus, Salix, Populus y otras, en densidades de 2 a 4 mil plantas por hectárea y rotaciones de 2 a 5 años. Estas plantaciones normalmente son objeto de silvicultura intensiva, que incluye cuidadosa selección de especies (híbridos en algunos casos), fuertes técnicas de establecimiento, control de competencia (malezas), fertilización e incluso riegos. En Brasil, empleando híbridos de Eucalyptus, se han registrado crecimientos de hasta $100 \mathrm{~m}^{3} /$ ha/año.

Perspectivas importantes en el caso chileno es que estas especies permitirían utilizar para estos fines suelos forestales o ganaderos en desuso, que son marginales para los cultivos forestales tradicionales de Pinus radiata, Eucalyptus globulus ssp globulus y Eucalyptus nitens, y que para estas plantaciones podrían aplicarse los incentivos estatales de la legislación vigente para plantaciones en suelos degradados, para plantaciones de pequeños y medianos propietarios y para plantaciones dendroenergéticas. La masificación de plantaciones de este tipo cumpliría así con beneficios económicos, sociales y ambientales, múltiples en el último caso al cumplirse con protección y recuperación de suelos, captura de carbono atmosférico y reemplazo de combustibles fósiles.

La investigación de INFOR señala que algunas especies de Acacia pueden ser empleadas en amplias zonas del país, sin mayor competencia con otros usos del suelo como agricultura, ganadería y plantaciones de pino y eucalipto (Pinilla et al., 2010).

Acacia dealbata, en diferentes ensayos realizados por INFOR muestra interesantes resultados de crecimiento en altura y diámetro, con incrementos volumétricos anuales de $20 \mathrm{~m}^{3 /}$ ha, similares a los obtenidos con Pinus radiata y Eucalyptus gobulus en diversos sitios (Pinilla y Hernández, 2005). Su madera tiene una buena aptitud para diferentes usos, como aserrío, chapas, pulpa y otros, y es de buena trabajabilidad (Anexo $N^{\circ} 1$ ).

que "la riqueza en bosques es el bienestar de la nación". Sus ideas centrales fueron la recuperación de los terrenos degradados y de los cultivos marinos y el impulso a las plantaciones forestales con fines comerciales y a la creación de áreas silvestres protegidas.

364 / Ciencia e Investigación Forestal - Instituto Forestal / Chile 
Su madera es apreciada como leña y para la producción de carbón, no obstante no existe mucha información técnica respecto de su uso como combustible. La literatura señala que su poder calorífico es alto, de $4.700 \mathrm{Kcal} / \mathrm{Kg}$, similar a roble y mayor que espino,

El establecimiento de nuevas plantaciones forestales, con fines exclusivamente energéticos y en cortas rotaciones, con o sin incentivos económicos provistos por el Estado, es una muy interesante alternativa de desarrollo rural para pequeños y medianos propietarios. No obstante, esto debe ser respaldado por investigación sobre especies a emplear, su manejo y las herramientas de gestión, y fundamentalmente, el conocimiento de la calidad como combustible de sus maderas, sus rendimientos y las técnicas de producción, transformación y distribución de la energía con ellas generada.

INFOR, dentro de su programa de investigación con acacias, ha abordado esta línea específicamente para producción de dendroenergía. Para esto se han establecido plantaciones experimentales para la obtención de antecedentes de crecimiento, rendimiento, productividad en biomasa y su relación con la capacidad dendroenergética de la especie, según diferentes espaciamientos iniciales, áreas geográficas, y edades de cosecha. Los espaciamientos iniciales son de $0,5 \times 0,5 \mathrm{~m}, 1 \times 1 \mathrm{~m}, 2 \times 2 \mathrm{~m}, 3 \times 3 \mathrm{~m}, 1 \times 0,5 \mathrm{~m}, 1 \times 2 \mathrm{~m}, 1 \times 3 \mathrm{~m}, 2 \times 0,5 \mathrm{~m}, 2 \times 2 \mathrm{~m}, 3$ x 0,5 m y $3 \times 1 \mathrm{~m}$. Se obtendrán periódicamente muestras de madera de estos ensayos para estudiar si se registran variaciones en densidad y poder calorífico de esta con la edad, y según densidad de plantación.

Independientemente de estos ensayos, por ahora se ha determinado el poder calorífico de la madera de esta especie a base de muestras obtenidas de rodales de ensayos anteriores de diferentes edades en las regiones del Maule y Bio Bio, y sus resultados se entregan en el presente trabajo. 

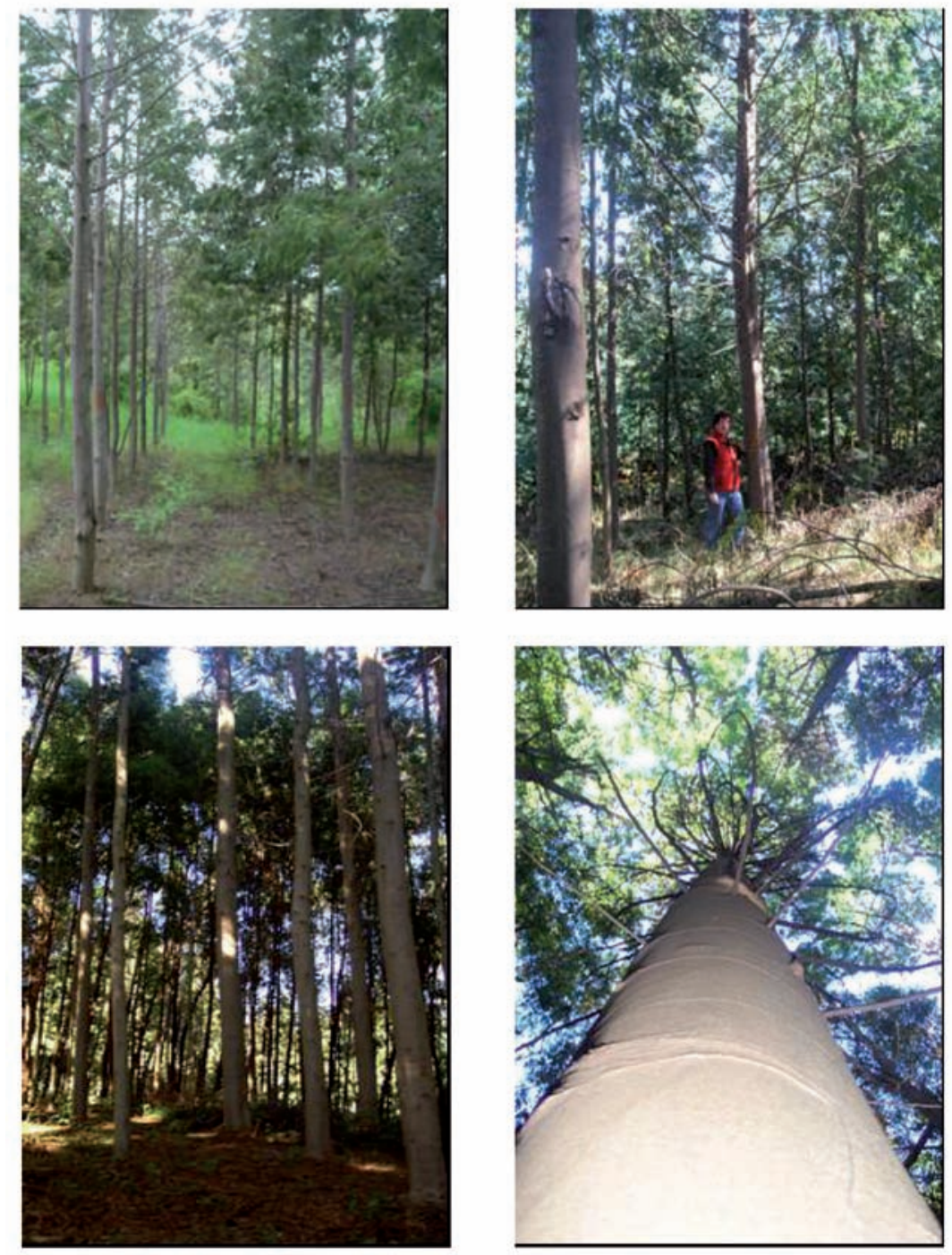

Figura $\mathrm{N}^{\circ} 7$

RODALES DE Acacia dealbata EN DIFERENTES SITIOS YUMBEL, YUNGAY y ANTIQUINA, REGIÓN DEL BIO BIO, Y RETIRO, REGIÓN DEL MAULE

\section{Poder Calorífico}

El Poder Calorífico (PC) de un combustible es la cantidad de energía desprendida durante la reacción de combustión, referida a la unidad de masa del combustible. 
La composición de la madera es determinante en la magnitud del poder calorífico. Los valores altos están ligados a las especies más lignificadas, más densas y con mayor contenido de resinas, terpenos y aceites esenciales. El poder calorífico crece a medida que se lignifican los tejidos y disminuye con el aumento del contenido de humedad.

Existen dos mediciones para el poder calorífico; el Poder Calorífico Superior (PCS) y el Poder Calorífico Inferior (PCl). El primero corresponde al calor desprendido en la combustión completa de 1 kilo de combustible cuando el vapor de agua originado en la combustión está condensado y se contabiliza el calor desprendido en este cambio de fase, el PCl en tanto, es la cantidad de calor desprendido en la combustión completa de 1 kilo de combustible sin contar la parte correspondiente al calor latente del vapor de agua de la combustión, ya que no se produce cambio de fase, y se expulsa como vapor.

\section{OBJETIVO DEL ESTUDIO}

Determinar el Poder Calorífico Superior e Inferior de muestras de madera de Acacia dealbata creciendo en distintas localidades y a diferentes edades, entre las regiones del Maule y Bio Bio.

\section{METODOLOGÍA}

Para este estudio se seleccionaron 7 rodales de Acacia dealbata correspondientes a ensayos establecidos por INFOR entre la región del Maule y la región del Bio Bio. Los antecedentes de cada rodal se presentan en el Cuadro $\mathrm{N}^{\circ} 1$, y la información dasométrica en el Cuadro $\mathrm{N}^{\circ} 2$ y la descripción de las muestras en el Cuadro $\mathrm{N}^{\circ} 3$ y Figura $\mathrm{N}^{\circ} 8$.

Cuadro $\mathrm{N}^{\circ} 1$

ANTECEDENTES DE LOS RODALES DE DONDE SE OBTUVIERON LAS MUESTRAS

\begin{tabular}{|c|c|c|c|c|}
\hline RODAL & AÑO PLANTACIÓN & NOMBRE PREDIO & REGION & COMUNA \\
\hline 90 & 2005 & COPIHUE & MAULE & RAFAEL \\
\hline 80 & 2003 & FARELLÓN & BIO BIO & CAÑETE \\
\hline 82 & 2003 & QUINAHUE & BIO BIO & LEBU \\
\hline 102 & 2004 & SAN ANTONIO CUDA & BIO BIO & FLORIDA \\
\hline 103 & 2004 & SANTA TERESA & BIO BIO & TOME \\
\hline 104 & 2004 & EL MAGNOLIO & BIO BIO & FLORIDA \\
\hline
\end{tabular}




\section{Cuadro $\mathrm{N}^{\circ} 2$.}

\section{DESCRIPCIÓN DASOMÉTRICA DE LOS RODALES}

\begin{tabular}{|l|l|l|l|l|l|l|l|l|}
\hline RODAL & PREDIO. COMUNA & $\begin{array}{l}\text { EDAD } \\
(\text { Años })\end{array}$ & $\begin{array}{l}\text { ALTURA } \\
\text { MEDIA } \\
(\mathbf{m})\end{array}$ & $\begin{array}{l}\text { DAP } \\
\text { MEDIO } \\
(\mathbf{c m})\end{array}$ & $\begin{array}{l}\text { VOLUMEN } \\
(\mathbf{m} 3 / \mathbf{h a})\end{array}$ & $\begin{array}{l}\text { ÁREA } \\
\text { BASAL } \\
(\mathbf{m} 2 / \mathbf{h a})\end{array}$ & $\begin{array}{l}\text { ALTURA } \\
\text { DOMINANTE } \\
(\mathbf{m})\end{array}$ & $\begin{array}{l}\text { DENSI- } \\
\text { DAD } \\
\text { (ÁRB/ha) }\end{array}$ \\
\hline 80 & Farellón. Cañete & 3,95 & 11,06 & 118,6 & 93,307 & 19,710 & 12,5 & 1.660 \\
\hline 82 & Quinahue. Lebu & 3,95 & 8,74 & 128,8 & 77,583 & 21,093 & 9,09 & 1.540 \\
\hline 102 & San Antonio. Florida & 3,23 & 7,03 & 63,4 & 26,774 & 5,294 & 8,58 & 1.580 \\
\hline 103 & Santa Teresa. Rafael & 3,23 & 9,18 & 88,9 & 37,886 & 8,494 & 9,51 & 1.280 \\
\hline 104 & Huaro Alto. Florida & 3,23 & 7,29 & 66,6 & 27,583 & 5,602 & 8,97 & 1.500 \\
\hline 96 & Copihue. Parral & 4,78 & 15,50 & 140,1 & 137,797 & 22,663 & 17,43 & 1.400 \\
\hline
\end{tabular}

Cuadro $\mathrm{N}^{\circ} 3$

\section{ANTECEDENTES DE LAS MUESTRAS UTILIZADAS EN EL ESTUDIO}

\begin{tabular}{|l|c|c|}
\hline ORIGEN & $\begin{array}{c}\text { DIÁMETRO SECCIÓN } \\
\text { (cm) }\end{array}$ & $\begin{array}{c}\text { EDAD } \\
\text { (Años) }\end{array}$ \\
\hline Huaro Alto. Florida & 23,0 & 5 \\
San Antonio. Florida & 8,5 & 5 \\
Copihue. Parral & 14,0 & 4 \\
Copihue. Parral & 16,0 & 4 \\
Farellón. Cañete & 19,0 & 6 \\
Santa Teresa. Rafael & 17,0 & 5 \\
Quinahue. Lebu & 18,0 & 6 \\
\hline
\end{tabular}
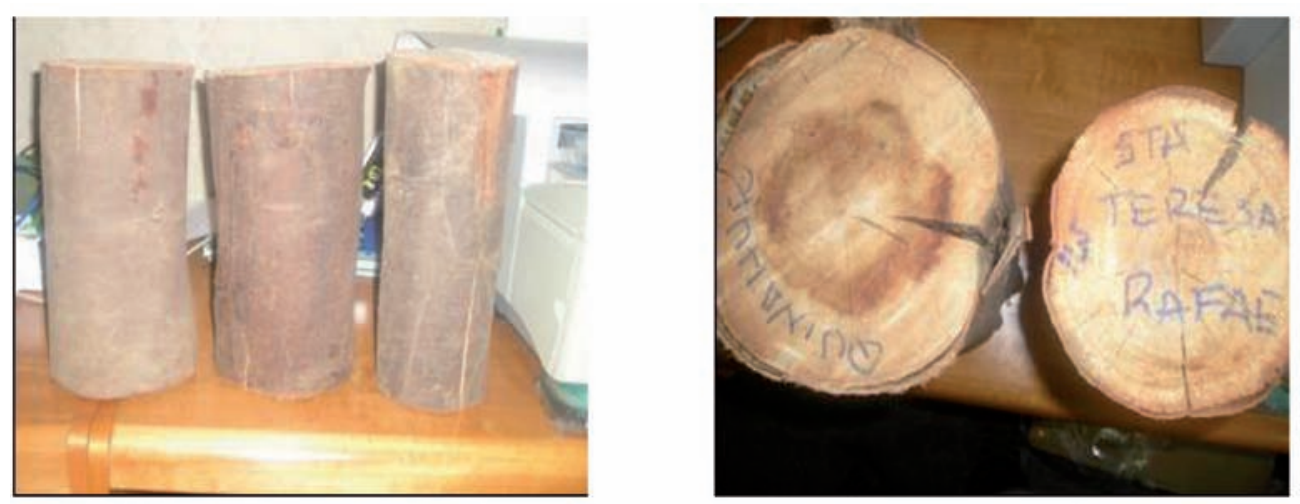

Figura $\mathrm{N}^{\circ} 8$

MUESTRAS UTILIZADAS EN EL ESTUDIO

El rodal de mayor edad, Farellón, Cañete, fue establecido usando semilla australiana, mientras que el resto de los rodales fueron plantados utilizando semillas provenientes de árboles superiores seleccionados en el país. Este detalle puede influir en los resultados a obtener. 
En cada rodal se seleccionaron 3 árboles con un DAP cercano al promedio del rodal. Estos árboles fueron volteados y una sección de $30 \mathrm{~cm}$ a la altura del DAP fue seleccionada para su traslado a laboratorio. De cada sección se obtuvo la muestra que se utilizó en la determinación de los poderes caloríficos de la madera.

Las determinaciones del PCS fueron ejecutadas en la Universidad del Bío Bío, Departamento de Ingeniería Mecánica, Área de Termofluidos.

Previo a la determinación del PCS, a cada muestra de madera ensayada se le determinó el contenido de humedad y densidad básica y de referencia.

El material combustible ( \pm 1 gramo) fue dispuesto en el crisol de la bomba calorimétrica, elemento que considera un alambre para el encendido del combustible. La bomba fue cargada con oxígeno puro a una presión de 20 Atmósferas y el crisol ubicado dentro del equipo calorímetro, rodeado por agua $(1.900 \mathrm{~g})$ a objeto de absorber el calor generado por la combustión. El equipo presenta una camisa exterior y una separación de aire estanco, que minimiza las pérdidas de calor al ambiente (Figura $N^{\circ}$ 9).

Los equipos empleados para la determinación del PCS fueron:

- Bomba calorimétrica Parr: serial: 3274, ítem: 1341.

- Unidad de ignición Parr: cat. № 2901, lot. № 186.

- Balanza Precisa: modelo 500M-2000c, rango 0-2.200 g., precisión 0,001 g.

- Termómetro Extech: precisión RTD 407907, sonda PT 3850, precisión 0,01ํ․

- Cronometro Lithuim Extech 0,01 segundos. 


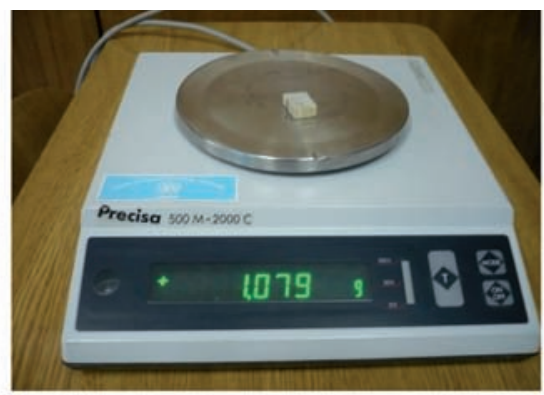

Determinación peso probetas

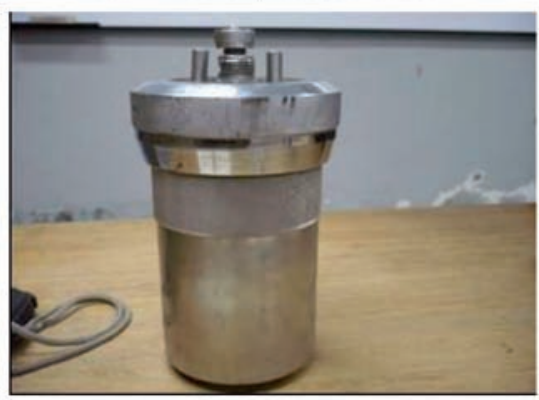

Bomba calorimétrica

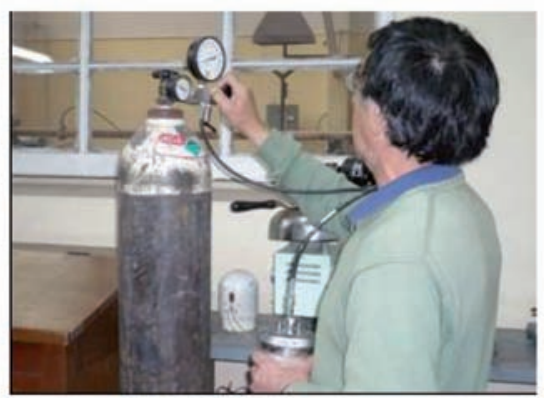

Lectura de presión de oxígeno

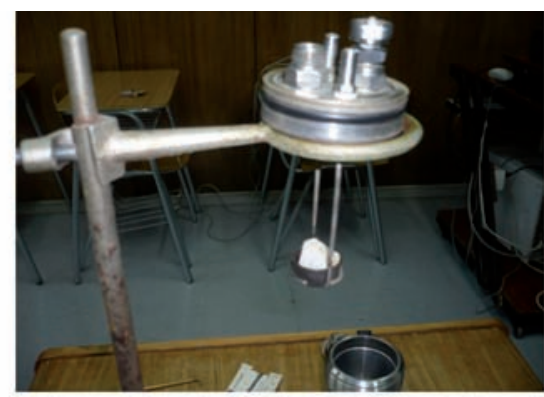

Probeta en crisol de bomba calorimétrica

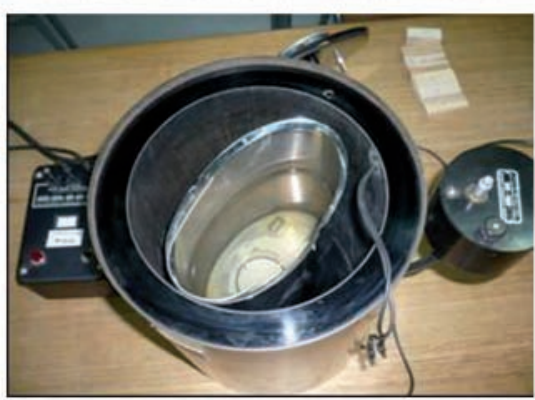

Equipo calorimétrico (aire, agua, estanco)

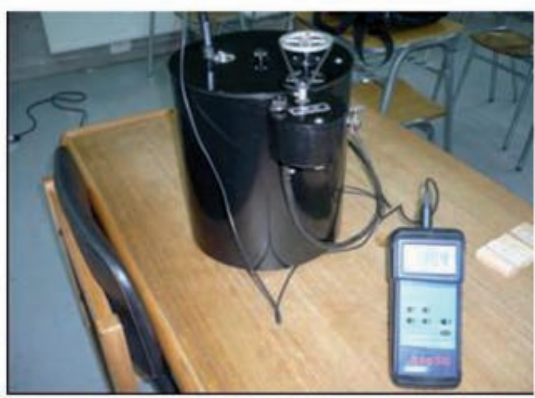

Equipo y lectura temperatura durante combustión

Figura $\mathrm{N}^{\circ} 9$

\section{EQUIPO CALORIMÉTRICO}

La fórmula utilizada para determinar el $\mathrm{PCl}$ (base húmeda) es la que se indica ${ }^{12}$ :

$$
\mathrm{PCl}=\mathrm{PCS}-600 *\left(\mathrm{CH}+9 * \mathrm{H}_{2}\right)
$$


Donde:

$\mathrm{PCl}=$ Poder calorífico inferior (Kcal $/ \mathrm{kg}$ combustible húmedo)

PCS = Poder calorífico superior (Kcal $/ \mathrm{kg}$ combustible húmedo)

$600=$ Calor latente de vaporización del agua $(\mathrm{kcal} / \mathrm{kg})$

$\mathrm{CH}=$ Contenido de humedad en base húmeda del combustible

$\mathrm{H}_{2} \quad=$ Fracción en peso del hidrógeno presente en el combustible (0.061 $\mathrm{kgH}_{2} / \mathrm{kg}$ combustible)

\section{RESULTADOS}

\section{Contenido de Humedad y Densidad}

Realizados los análisis se obtuvieron el contenido de humedad y las densidades básica y de referencia, información que se presenta en el Cuadro $N^{\circ} 4$ y la Figura $N^{\circ} 10$.

\section{Cuadro $\mathrm{N}^{\circ} 4$ \\ CONTENIDO DE HUMEDAD Y DENSIDAD}

\begin{tabular}{|l|c|c|c|c|}
\hline Origen & $\begin{array}{c}\mathbf{C H}\left(\mathbf{b h}^{*}\right) \\
(\%)\end{array}$ & $\begin{array}{c}\text { Edad } \\
(\mathbf{A n n o s})\end{array}$ & $\begin{array}{c}\text { Densidad Básica } \\
\mathbf{( \mathbf { k g } / \mathbf { m } ^ { 3 } )}\end{array}$ & $\begin{array}{c}\text { Densidad } \\
\text { Referencia } \mathbf{( k g / \mathbf { m } ^ { 3 } )}\end{array}$ \\
\hline Huaro Alto. Florida & 9,26 & 5 & 544,44 & 639,27 \\
San Antonio. Florida & 10,90 & 5 & 474,40 & 603,17 \\
Copihue. Parral & 12,99 & 4 & 353,87 & 538,10 \\
Copihue. Parral & 12,50 & 4 & 434,56 & 521,67 \\
Farellón. Cañete & 11,17 & 6 & 318,64 & 369,90 \\
Santa Teresa. Rafael & 10,59 & 5 & 463,92 & 584,32 \\
Quinahue. Lebu & 12,69 & 6 & 322,52 & 427,41 \\
\hline
\end{tabular}

*bh: Base húmeda

La densidad básica es la que relaciona la masa anhidra de la madera y su volumen en estado saturado, mientras que la de referencia es la que relaciona la masa y el volumen a un mismo contenido de humedad. 


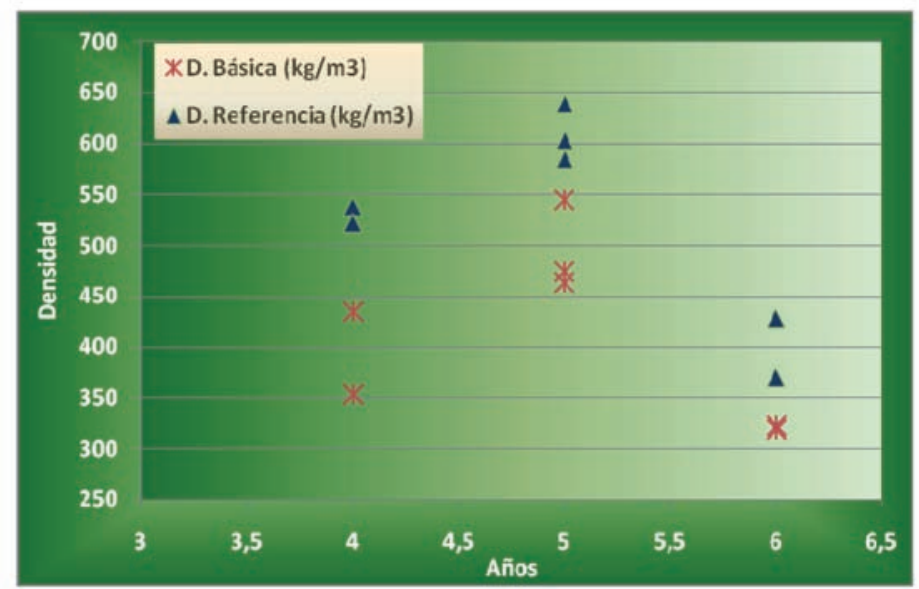

FIGURA N ${ }^{\circ} 10$

DENSIDADES OBTENIDAS

Al observar las densidades resultantes, un primer análisis señala que los árboles o rodales de mayor edad presentan una menor densidad, asociada a un mayor crecimiento. Estos árboles provenienen de semilla australiana. Por el contrario, los árboles de mayor densidad corresponden a semilla de raza local, los cuales según la información del Cuadro №2 están creciendo a una menor tasa, generando una mayor densidad de la madera, lo que explicaria el resultado obtenido. Este resultado debe ser corroborado en edades superiores.

\section{Poder Calorífico}

Los poderes caloríficos superior e inferior obtenidos a partir de muestras de Acacia dealbata se presentan en el Cuadro $N^{\circ} 5$ y Figura $N^{\circ} 11$.

\section{Cuadro $\mathrm{N}^{\circ} 5$}

PODERES CALORÍFICOS OBTENIDOS EN Acacia dealbata

\begin{tabular}{|c|c|c|c|c|c|c|c|}
\hline \multirow{3}{*}{ Origen } & \multirow{3}{*}{$\begin{array}{c}\mathrm{CH} \\
\text { (bh) } \\
(\%)\end{array}$} & \multirow{3}{*}{$\begin{array}{l}\text { Edad } \\
\text { (Años) }\end{array}$} & \multicolumn{3}{|c|}{$\begin{array}{c}\text { PCS } \\
(\mathrm{Kcal} / \mathrm{Kg})\end{array}$} & \multirow{3}{*}{$\begin{array}{c}\text { PCS } \\
\text { Promedio } \\
\text { (Kcal/Kg) }\end{array}$} & \multirow{3}{*}{$\begin{array}{l}\text { PCI Promedio } \\
\text { (Kcal/Kg) }\end{array}$} \\
\hline & & & \multicolumn{3}{|c|}{ Muestra } & & \\
\hline & & & 1 & 2 & 3 & & \\
\hline Huaro Alto & 9,26 & 5 & $3.963,65$ & $3.893,30$ & $3.871,43$ & $3.909,46$ & $3.524,52$ \\
\hline San Antonio & 10,90 & 5 & $4.241,01$ & $3.876,33$ & $3.914,26$ & $4.010,53$ & $3.615,75$ \\
\hline Copihue & 12,99 & 4 & $3.804,76$ & $4.018,20$ & $3.963,35$ & $3.928,77$ & $3.521,43$ \\
\hline Copihue & 12,50 & 4 & $4.144,34$ & $4.065,98$ & $4.056,72$ & $4.089,01$ & $3.684,59$ \\
\hline Farellón & 11,17 & 6 & $4.001,69$ & $3.918,51$ & $3.827,61$ & $3.915,94$ & $3.519,49$ \\
\hline Santa Teresa & 10,59 & 5 & $4.146,57$ & $4.141,96$ & $4.013,73$ & $4.100,75$ & $3.707,78$ \\
\hline Quinahue & 12,69 & 6 & $4.373,02$ & $4.183,80$ & $4.308,85$ & $4.288,56$ & $3.883,04$ \\
\hline Promedio & & & & & & $4.034,71$ & $3.636,65$ \\
\hline
\end{tabular}




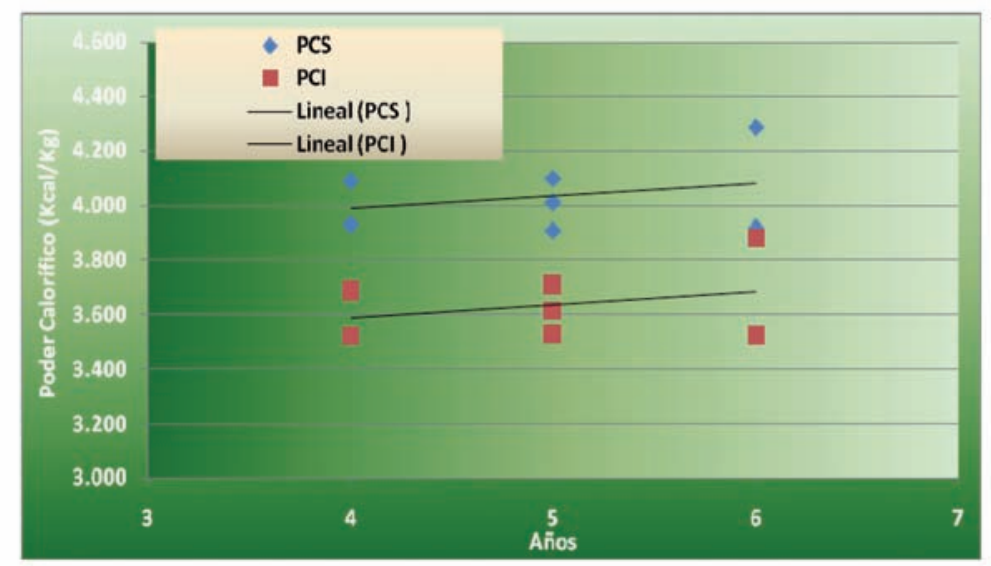

Figura $\mathrm{N}^{\circ} 11$

RESULTADOS DE PODER CALORÍFICO EN Acacia dealbata

Los resultados anteriores son concordantes, con información bibliográfica existente en otros países, aunque algo inferiores, llegando a un máximo de cercano a $4.300 \mathrm{Kcal} / \mathrm{Kg}$ en relación al valor de $4.700 \mathrm{Kcal} / \mathrm{Kg}$ para el PCS que da la bibliografía.

Como comparación, en el Cuadro $N^{\circ} 6$ se presentan los PCS de algunas especies que crecen en Chile, según Covacevich (1979) para madera seca en horno.

Cuadro $N^{\circ} 6$.

PODERES CALORÍFICOS SUPERIORES

DE ESPECIES FORESTALES QUE CRECEN EN CHILE

\begin{tabular}{|l|c|}
\hline Especie & PCS \\
(Kcal/Kg)
\end{tabular}




\section{ANÁLISIS DE LOS RESULTADOS}

Los resultados de los ensayos de INFOR demuestran que algunas especies de Acacia que crecen en el país son promisorias para ser utilizada en futuros programas de forestación.

Durante el desarrollado esta línea de investigación de INFOR, se ha analizado un conjunto de resultados que en sí constituyen un aporte y un logro en el trabajo con acacias. Sin embargo, se requiere de más investigaciones, nuevos ensayos e información para generar las alternativas económicas; silvicultura y esquemas de manejo en función de diferentes productos, entre ellos la dendroenergía.

El rápido desarrollo de Acacia dealbata, su capacidad de rebrote desde tocón, su adaptabilidad a suelos degradados y su relativamente fácil silvicultura, hacen que la especie presente un alto potencial para el uso en energía.

La determinación de su poder calorífico así lo confirma, aunque resultando menor que los que entrega la bibligrafía, estas determinaciones deberán complmentarse con muestras porvenientes de más sitios, mayores edades y una variedad de densidades de plantación para producción de dendroenergía en cortas rotaciones.

Se podrá así caracterizar la calidad de la biomasa generada en relación a su poder calorífico, edad y sitio de crecimiento, junto con establecer los esquemas silviculturales que permitann la producción sustentable de biomasa.

Al considerar la cantidad de materia seca producida en cada espaciamiento utilizado, por ejemplo, relacionando el volumen registrado y la densidad anhidra de la madera $\left(318 \mathrm{Kg} / \mathrm{m}^{3}\right.$ en el caso de Acacia dealbata), será posible obtener la biomasa seca total, identificando aquellos espaciamientos que registren la mayor acumulación de biomasa en un tiempo determinado.

Los resultados obtenidos con futuros estudios del poder calorífico de la madera de Acacia dealbata en diferentes densidades y edades, permitirán obtener la relación óptima entre cantidad de biomasa y poder calorífico, escenario que hará posible definir los esquemas de manejo sustentables para plantaciones con esta especie destinada a energía.

Los primeros resultados indican que las densidades obtenidas en los árboles de mayor edad son más bajos, lo que muy probablemente se asocia a que estos rodales presentan a la fecha un gran ritmo de desarrollo (Farellón y Quinahue) en relación a los otros rodales. El origen de estos árboles corresponde a semilla australiana, en tanto que los árboles que presentaron una mayor densidad a partir de la muestra utilizada provienen de semilla de raza local, árboles Plus selecciondados de diferentes ensayos y rodales en el país, los cuales están creciendo a una menor tasa, pero generando una mayor densidad de la madera, lo que explicaria el resultado obtenido. Este resultado deberá ser corroborado en estudios posteriores.

Los resultados de este estudio son concordantes con información bibliográfica existente, con valores cercanos a las $4.700 \mathrm{Kcal} / \mathrm{Kg}$ para PCS, similar a otras especies forestales que crecen en el país, con la diferencia que estas corresponden a especies del Bosque Nativo, 
como lo es el Roble (Nothofagus obliqua) y Espino (Acacia caven),

En España, en la zona de Galicia. A esta especie se le están buscando opciones de utilización para la biomasa debido a su rápido crecimiento (Valero et al., s/f), y se han obtenido valores iniciales de PCS de 4.700 a $4.800 \mathrm{kcal} / \mathrm{Kg}$, mientras que el PCl varió entre los 3.000 a $4.000 \mathrm{kcal} / \mathrm{kg}$. Los autores concluyen que esta madera puede ser usada con fines energéticos, agregando que el costo de extracción y transporte determinarán su uso en este tipo de producto $^{13}$.

La evaluación realizada en este estudio se considera adecuada para los objetivos de la investigación, ya que se trata de rodales entre los 4 y 6 años de edad, edades que se supone serán suficientes para una rotación con objetivos dendroenergéticos.

Las muestras utilizadas en la determinación del poder calorífico de la madera de Acacia dealbata provienen de árboles de poca edad, madera 100\% juvenil, entre 4 y 6 años. Esta condición, es decir, tejidos ricos en celulosa y pobres en lignina, explican los valores de poder calorífico determinados.

Los PCS de las muestras de madera ensayadas por Covacevich (1979) son mayores que los determinados para las muestras de Acacia dealbata, probablemente influenciados por la menor humedad y la mayor densidad de la madera.

Dado que el $\mathrm{PCl}$ es función de la humedad, a menor humedad, se obtiene un mayor $\mathrm{PCl}$ por lo que se necesita una menor cantidad de biocombustible para producir una unidad de energía. De ahí la importancia de contar con especies cuya biomasa entregue un alto valor del PCI. Un mayor poder calorífico genera evidentemente una biomasa de mayor calidad energética.

En un proceso productivo esta biomasa debería una vez extraída pasar por un proceso de secado y densificación, a través de su trituración y compactación de modo de obtener un combustible más eficiente.

\section{CONCLUSIONES}

La capacidad de rebrotar desde tocón, unido a su rápido desarrollo, su adaptabilidad a suelos degradados y relativamente fácil silvicultura, hace que Acacia dealbata presente un alto potencial para su uso en energía.

Los resultados del estudio del poder calorífico junto con los ensayos de bioenergía con Acacia entregarán importantes elementos de discusión.

Con los resultados de la investigación se podrá caracterizar la calidad de la biomasa generada en relación a su poder calorífico, edad y sitio de crecimiento. El conocimiento de su crecimiento en diferendtes condiciones, asociado a la calidad de la biomasa para energía,

13 http://www.esac.pt/cernas/cfn5/docs/T4-21.pdf 
permitirá establecer los esquemas silviculturales que permitann la producción sustentable de biomasa.

Se requiere corroborar la influencia de las tasas de crecimiento y el origen de la semilla en relación con la densidad de la madera.

Se obtuvieron valores promedio de $4.034,71$ y $3.636,65 \mathrm{Kcal} / \mathrm{kg}$ para los valores de PCS y $\mathrm{PCl}$, respectivamente.

Las muestras utilizadas provienen de árboles de poca edad, madera 100\% juvenil, entre 4 y 6 años. Lo que explican los valores de poder calorífico determinados.

Los resultados del estudio son concordantes con información bibliográfica existente, y similar a otras especies forestales nativas que crecen en el país,

La evaluación realizada en este estudio se considera adecuada para los objetivos de la investigación, ya que se trata de rodales entre los 4 y 6 años de edad, edades que se supone serán suficientes para una rotación con objetivos dendroenergéticos.

Todos estos resultados son iniciales y fundamentales para efectuar una selección más certera de las especies, árboles y esquemas silvícolas con mejor desempeño para producción de biomasa.

\section{REFERENCIAS}

Barros, A, S., 2007. El Género Acacia, Especies Multipropósito. En: Ciencia e Investigación Forestal Número Extraordinario. Instituto Forestal, Chile.

CNE, 2009. Introducción de Energías Renovables No Convencionales, Biomasa. Comisión Nacional de Energía, Chile. En línea:http://www.cne.cl/cnewww/opencms/03_Energias/ Otros_Niveles/renovables_noconvencionales/Tipos_Energia/biomasa.html.

Covacevich, R,. 1979. Poder Calorífico de Pino Insigne y de otras especies forestales chilenas. Universidad de Chile. 1979.

Hernández, G. y Pinilla, J. C., 2009. Compendio Propiedades de la Madera de Especies Nativas y Exóticas en Chile. Informe Técnico N 178. Instituto Forestal, Sede Bio Bio, Chile.

Pinilla S., J.C. y Hernández C., G., 2005. Antecedentes Generales Sobre Propiedades y Utilización de la Madera. En: Pinilla, J.C.; Molina, M. y Gutiérrez, B. (editores). Investigación con Acacia dealbata, A. melanoxylon y A. mearnsii en Chile. INFOR-CORFO. Concepción, Chile. Pp: 99-111.

Pinilla, J.C.; Molina, M.P.; Hernández, G.; Barros, S.; Ortiz, O. y Navarrete, M., 2010. Avances de la investigación con especies del género Acacia en Chile. Informe Técnico $\mathrm{N}^{\circ}$ 179. Instituto Forestal, Sede Bio Bio, Chile. 
Valero, E., Picos, J., Ortíz , L., Valentin, G., González, N. s/f. Propiedades bioenergéticas de las masas de Acacia dealbata Link. Universidad de Vigo, Escuela Universitaria de Ingeniería Técnica Forestal. Pontevedra, España. 9p. 


\section{ANEXO $\mathbf{N}^{\circ} 1$ \\ PROPIEDADES FÍSICAS Y MECÁNICAS APTITUDES DE USO DE LA MADERA DE Acacia dealbata}

Como parte del programa de investigación con especies del género Acacia, fueron estudiadas las propiedades físicas y mecánicas de la madera de Acacia dealbata que crece en Chile y sus aptitudes de usos para diferentes productos (Pinilla y Hernández, 2005; Hernández y Pinilla, 2009; Pinilla et al., 2010). Los resultados se presentan resumidamente a continuación.

\section{Propiedades Físicas y Mecánicas}

\begin{tabular}{|c|c|c|c|}
\hline Ensayo & Parámetro & $\operatorname{Seco}(12 \%)$ & Verde \\
\hline Densidad $(\mathrm{kg} / \mathrm{m} 3)$ & & 439 & 499,00 \\
\hline \multirow{2}{*}{ Flexión (N/mm²) } & MOR & 92,86 & 62,07 \\
\hline & MOE & $11.959,33$ & $10.240,77$ \\
\hline \multirow{2}{*}{ Compresión (N/mm²) } & Paralela & 44,80 & 28,09 \\
\hline & Perpendicular & 9,36 & 6,51 \\
\hline \multirow{2}{*}{ Tracción Perpendicular (N/mm²) } & Radial & 3,76 & 3,10 \\
\hline & Tangencial & 4,29 & 4,27 \\
\hline \multirow{2}{*}{ Dureza $(\mathrm{N})$} & Paralela & 53,80 & 41,86 \\
\hline & Perpendicular & 34,85 & 33,46 \\
\hline \multirow{2}{*}{ Cizalle Paralelo $\left(\mathrm{N} / \mathrm{mm}^{2}\right)$} & Radial & 9,71 & 7,48 \\
\hline & Tangencial & 11,35 & 8,36 \\
\hline \multirow{2}{*}{ Clivaje (N/mm) } & Radial & 5,43 & 5,36 \\
\hline & Tangencial & 6,11 & 6,21 \\
\hline \multirow{2}{*}{ Tenacidad (Ncm) } & Radial & 28,67 & 24,33 \\
\hline & Tangencial & 33,00 & 26,95 \\
\hline \multirow{2}{*}{ Extracción Clavo $(\mathrm{N})$} & Paralela & 6,83 & 3,70 \\
\hline & Perpendicular & 9,96 & 6,42 \\
\hline
\end{tabular}

La corteza de esta especie es de un color café negruzco, dura y moderadamente fisurada, su albura es verde glauco-plateado, mientras que su duramen es de un castaño claro, rosado

\section{Características Tecnológicas y Aptitud de Uso}

\section{- Aserrado: Sin dificultad}

- Secado: Mediana dificultad, presecada bajo cobertizo y posteriormente secada en cámara no presenta grietas ni colapso. Bajo estas condiciones se observan alabeos de baja intensidad. Para madera aserrada de $25 / 50 \mathrm{~mm}$ de espesor, corte tangencial, radial o mixto; presecada al aire hasta un $25 / 30 \%$, se recomiendan programas constantes de $75 / 75^{\circ} \mathrm{C}-65 / 65^{\circ} \mathrm{C}$, respectivamente. 
- Chapas: Sin dificultad, presenta un buen comportamiento en el macerado y en la operación de foliado vertical. Las chapas no presentan problemas en el secado a alta temperatura $\left(130^{\circ} \mathrm{C}\right)$ como tampoco tendencia a la ondulación

- Encolado: Sin dificultad

- Trabajabilidad: Sin dificultad

- Cepillado: Se recomiendan 20 marcas/pulgada y ángulo ataque de $20^{\circ}$

- Lijado: Se recomienda velocidad avance de $4,5 \mathrm{~m} / \mathrm{min}$, lijas 80 y 120

- Moldurado: Se recomiendan 4 cuchillos, ángulos ataque y alivio de 18ํy y 19ํy y una velocidad de $7.000 \mathrm{rpm}$

- Escopleado: Se recomienda una velocidad de 8.500 rpm

- Torneado: Se recomienda una velocidad mayor a $3.000 \mathrm{rpm}$

- Taladrado: Se recomienda una velocidad mayor a $2.800 \mathrm{rpm}$

- Terminaciones: Sin dificultad, buenos resultados con barniz, laca y pintura

- Tratabilidad con CCA: Los polines no pueden impregnarse con el mismo programa que se utiliza para el Pinus radiata. Para alcanzar retenciones de 6,4 kilos de óxido/ $\mathrm{m}^{3}$ en polines con diámetro $2-4$ " se sugiere una concentración de la solución preservante en torno a un 4\% y una presión de trabajo de 230 PSI por 50 minutos, considerando una humedad de los polines entre 10/20\%

- Aptitud pulpable: Viable, la producción de celulosa de buenas características se obtiene al mezclar Eucalyptus globulus y $A$. dealbata, esta última hasta un $10 \%$

Las aplicaciones sugeridas para la madera de esta especie se concentran en pulpa, carpintería, fabricación de cajones, muebles rústicos y otros. 
